UDK 786.2.082.2 Šturm

\title{
KLAVIRSKA SONATA FRANCA ŠTURMA
}

\author{
Katarina B e d in a (Ljubljana)
}

Skladba je lep primer težnje klasikov 20. st., da bi v mogočni formi, ki se je razvijala dobri dve stoletji, našli oblikovni okvir za nov glasbeni izraz in za podobo sodobnega naziranja. Zamisel, kje naj se združijo nova kompozicijska načela $z$ bistvom doslej najvišje razvite glasbene oblike, je dala številné skladbe s tem naslovom. Vprašanje sodobne sonate je povezano $\mathrm{z}$ valom novega baročnega in klasicističnega ideala. Prve oḅlike že zanesljivega izražanja $\mathrm{v}$ različnih inačicah razširjene tonalnosti so terjale odgovarjajočo obliko. Preobrazba sonate je bila na vidnem mestu, saj je $z$ večjim ali manjšim uspehom vpregla ustvarjalni duh povsod, kjer se je spočel sodobni glasbeni nazor. Način preoblikovanja je bil, tako kot v sleherni novosti, odvisen izključno od domiselnosti in umetniške moči posameznikov, ki so utirali pota novi glasbi. Šturmova klavirska Sonata je izsek v konglomeratu teh poskusov ter izraz njegovih umetniških intencij.

Kompozicija je enajsto delo po kronološki ureditvi Śturmovih del, nastala pred študijem v Pragi (1932). Ta absolvent Osterčeve šole je toliko napredoval v kompozicijskem znanju, da je dospel do formata samostojnega ustvarjalca, ki »ima kaj povedati». V celem izredno plodne počitnice po absolutoriju ljubljanske šole pričajo o visoki umetniški ambiciji enaindvajsetletnega umetnika.

Znacilnosti dela skladno povezujejo posebnosti $\mathrm{v}$ oblikovnem in harmonskem oziru. Sonata je zamišljena kot ciklična oblika brez premora med stavki. Uvaja jo vsebinsko zaokrožen Sostenuto, sledi Allegro (vsebinsko in po obsegu težišče skladbe), nanj je navezan brez, prekinitve, ritardanda ali drugačne priprave Andante kot počasni stavek, temu sledita Allegro kot repriza sonatne ekspozicije, in coda. $\mathrm{V}$ osnovnih obrisih je oblikovna shema takale: uvod - AB - poćasni stavek - $\mathrm{A}_{1}$ - coda, podrobnejši prerez pa je naslednji:

$$
\begin{aligned}
& \text { takti: } \\
& 1-40 \\
& 41-185
\end{aligned}
$$

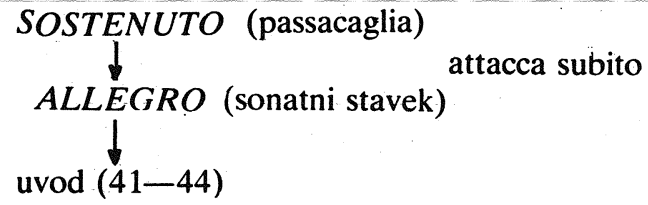




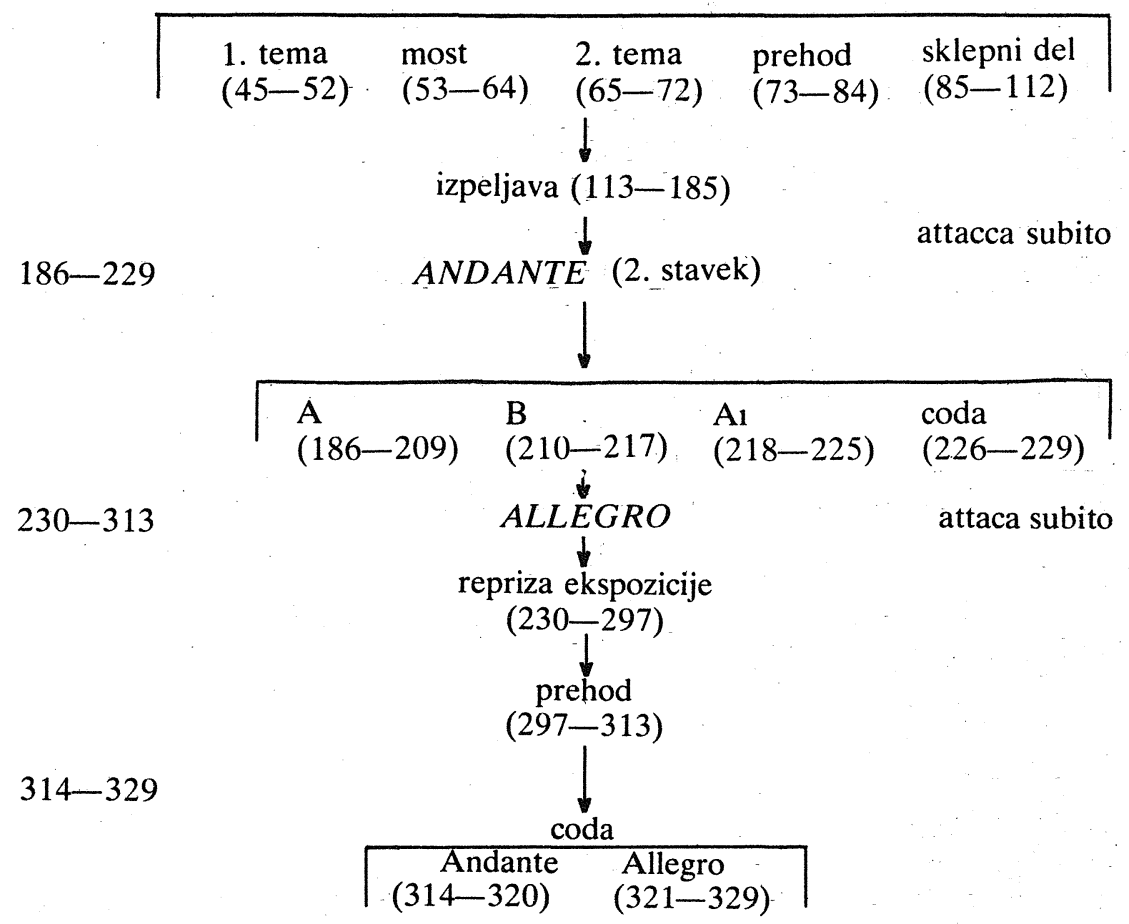

Šturm je v tem delu poskusil spojiti vse značilne lastnosti pojma sonate, ki se je razvil v naši zavesti, ne glede na različne razvojne vrste forme ter dobo in slog. Kompozicija je grajena tako, da vzbuja vtis skladateljeve volje, da bi se tudi sam sonatno izrazil - preizkusil »izrabljeno« formo za podobo lastnega umevanja glasbe in nove arhaičnosti.

Pri analizi skladbe lahko dojamemo štiri temeljna vodila in »zglede « iz tradicije, ki jim je Šturm sledil pri organskem povezovanju kompozicijskih prvin: v začetku preprostega, pozneje visoko razvitega vsebinskega okvira, od zgodnjega baroka do preloma s tradicijo:

a) značilno ponavljanje počasnih in hitrih delov, ki si sledijo brez premora, menjava sodih z lihimi taktovskimi načini ${ }^{1}$ (Sostenuto: tridelen, Allegro: štiridelen, Andante: petdelen, Allegro: štiridelen); način polifonskega mišljenja z motoričnimi učinki;

b) miselna povezanost in klasicistična odvỉsnost idej $\mathbf{v}$ tematiki;

c) simetrična periodizacija kljub posebnostim gradnje, členjenje notranjih sorazmerij, spajanje kontrastov v smislu enovitosti različnega;

d) intenzivno notranje dogajanje, prepredanje misli, dramatika in lirika $\mathbf{v}$ strogi organizaciji strukture, ki najde oporo $\mathrm{v}$ periodični harmonski zasnovi novega zvoka.

1 Prim. strukturo zgodnje baročne sonate (canzone) in sonate da chiesa. 
Uvodni stavek (Sostenuto) je passacaglia $s$ štiritaktno temo in devetimi variacijami. Ostinato se v nespremenjeni obliki ponavlja skozi vse variacije, le pri šesti je premaknjen iz spodnjega v zgornji basovski glas. Prva in četrta variacija sta dvoglasni, tema in štiri variacije so triglasne, ostale štiriglasne.

Stavek kot celota teče $v$ umirjenem toku, variacije ne razvijejo ostrejših kontrastov, filigranska razporejenost prvin ne opredeljuje »velikega « pomena, dimenzije posameznosti so usklajene $\mathrm{z}$ ne pretiranimi poudarki $\mathrm{v}$ nizanju malih period, vendar je navideżna tematična pritajenost tako zasnovana, da predstavlja $\mathrm{v}$ temi in nekaterih variacijskih pretvorbah miselno osnovo cele sonate. V začetku predstavljeni detajli opredelijo vse konstrukcijske in izrazne lastnosti skladbe.

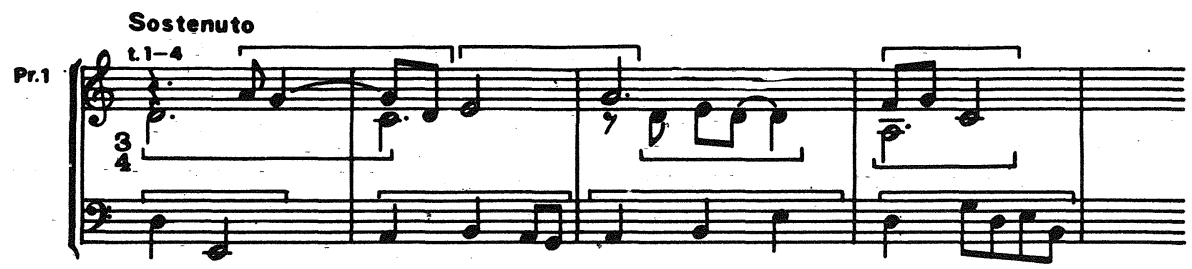

Kako so označene motivične prvine preoblikovane $\mathrm{v}$ sonatni tematiki, bo razvidno pri obravnavi ostalih stavkov. V zvezi s predstavljenim začetkom passacaglie si velja podrobneje ogledati harmonsko osnovo, ki je prav tako izhodišče zvočni gradnji v nadaljnjem toku sonate.

Preprosta, skoraj primitivna harmonska slika oziroma tonsko razmerje $\mathbf{v}$ melodičnem gibanju horizontale in vertikale, je premišljeno zastavljena: $\mathrm{v}$ posameznostih kot v skupnem učinku odraža neke vrste historično retrospektivo, spojitev predtonalnega, tonalnega ter razširjenega tonalnega mišljenja. Analiza notranjih zvočnih odnosov $v$ linearnem in vertikalnem pogledu kaže načrtno redukcijo sozvočij na štiri vodilne intervale: veliko sekundo (v obrnitvi nastopa tudi kot mala septima), malo terco, čisto kvarto ter čisto kvinto.

Zgornja dva glasova:

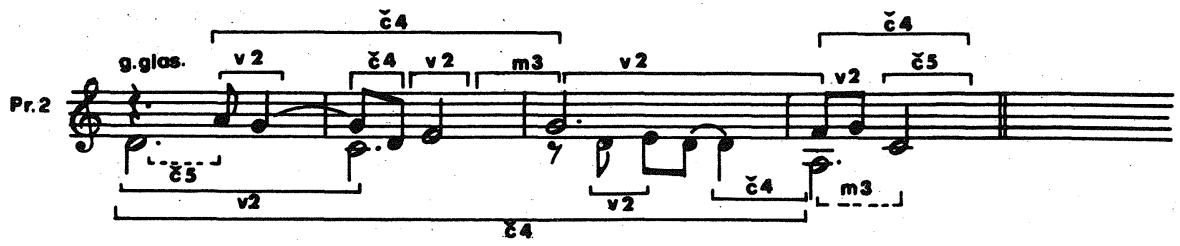

Ostinato:

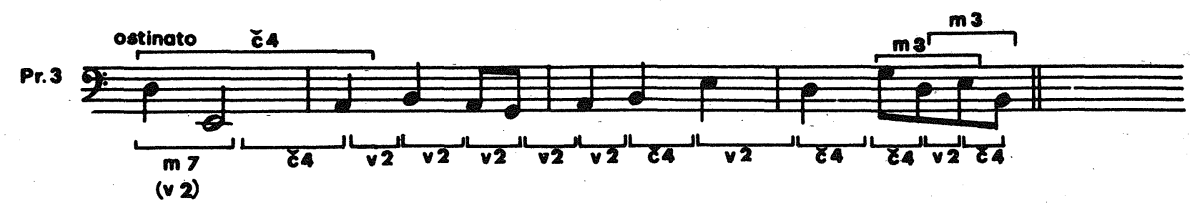


Za ostinato je še značilno, da je zgrajen iz pentatonske lestvice (brez poltona). Ta ustvarja arhaični prizvok, poleg tega s samo konstrukcijo daje za skladbo značilne intervale:

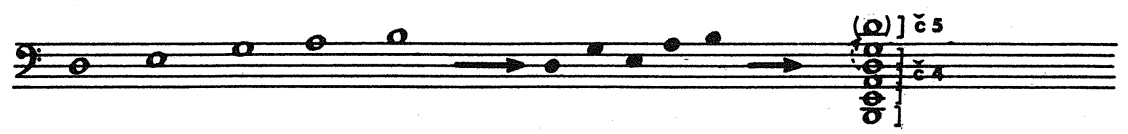

$\mathrm{V}$ vertikalnem pogledu je razmerje intervalov med glasovi oblikovano $\mathrm{v}$ podobni odvisnosti. Naslednji primer podrobneje kaže kvartne $(\longrightarrow)$ in sekundne odnose $(\rightarrow)$, pr. 5a pa vodilno strukturo intervalov $v$ vertikali:

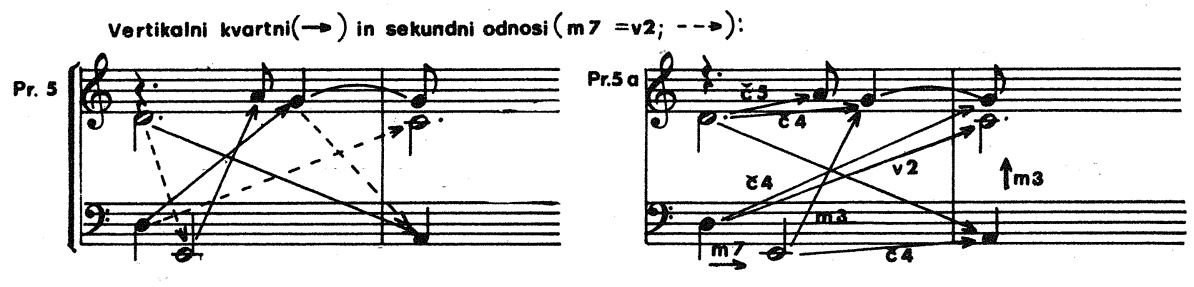

Iz primerov je razvidno, da je vsem glasovom skupen središčni ton d. Nanj različno inklinirajo, zgornji glasovi ga razvijejo $\mathrm{v}$ a-mol, D-dur in h-mol. Kombinacija in variiranje nakazanih sozvočij razvijeta zvočno paleto vse kompozicije. $\mathrm{V}$ kratkem: čista kvinta omogoča dozdevni odnos tonika-dominanta, mala terca molov karakter, posebno $\mathrm{v}$ delih $\mathrm{z}$ mešanjem durove in molove barve, čista kvarta novo gradnjo $\mathbf{v}$-izogib terčni, pentatonika reminiscenco na arhaični kolorit, obenem pa je pogosto sredstvo $v$ klasiki našega stoletja. Izpuščena je ostala obravnava prvega intervala, čiste oktave med basovskim in altovskim glasom. Za uvodno passacaglio ne odigra važnejše vloge kot to, da poudari središčni ton d, pomensko vrednost dobi na začetku sonatnega stavka in $\mathrm{v}$ codi.

Stiritaktni uvod $\mathrm{k}$ ekspoziciji sonatnega stavka začne $\mathrm{z}$ oktavno podvojitvijo tona fis (vodilni ton dominantine dominante središčnega tona d), ki skupaj $z$ malo septimo $\mathrm{v}$ zgornjih glasovih e-d (ta je identična $\mathrm{z}$ začetkom ostinata, pr. $7 \mathrm{cl}$ ) nakaže harmonsko osnovo stavka. Uvod se nadaljuje s tekočimi osminkami, te se $\mathbf{v}$ nadaljevanju $\mathrm{z}$ različnimi modifikacijami oblikujejo $\mathrm{v}$ dopolnilni glas pri tematični gradnji in postanejo eno od sredstev motoričnosti skladbe:

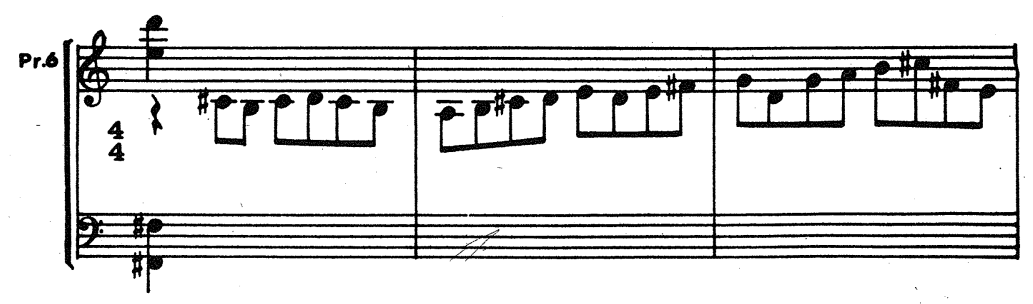

Uvod pripravi nastop prve teme na tonu d. Gradnja tematičnega gradiva sloni na motivičnih jedrih passacaglie, ki $\mathrm{v}$ osnovnih postavitvah zvenijo takole: 

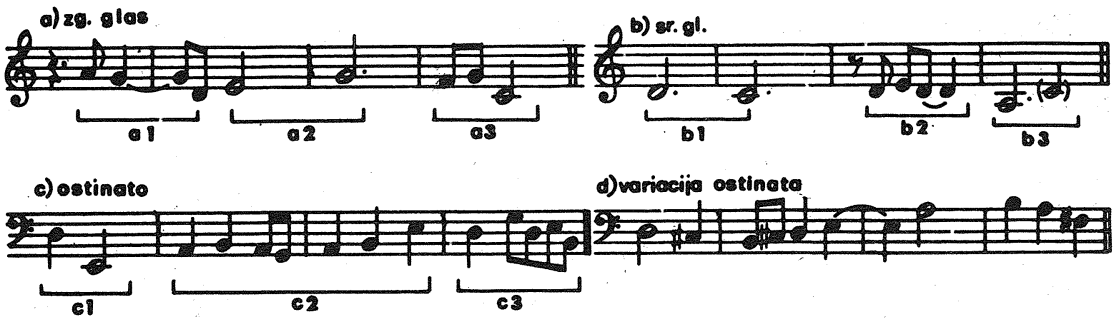

Po osnovni zamisli spominja stavek na značaj drugega fugiranega stavka baročne cerkvene sonate. Uvod (pr. 6) obeta fugo, vendar se razvoj misli oblikuje Y načinu klasicističnega tematičnega dela. Svoboden polifonijski izraz, ki pa temejito izrablja in presnavlja tematiko, do najmanjših fragmentov kot značilnost skladbe - enako izražena $\mathrm{v}$ manjših in večjih oblikovnih členih.

Začetek ekspozicije:

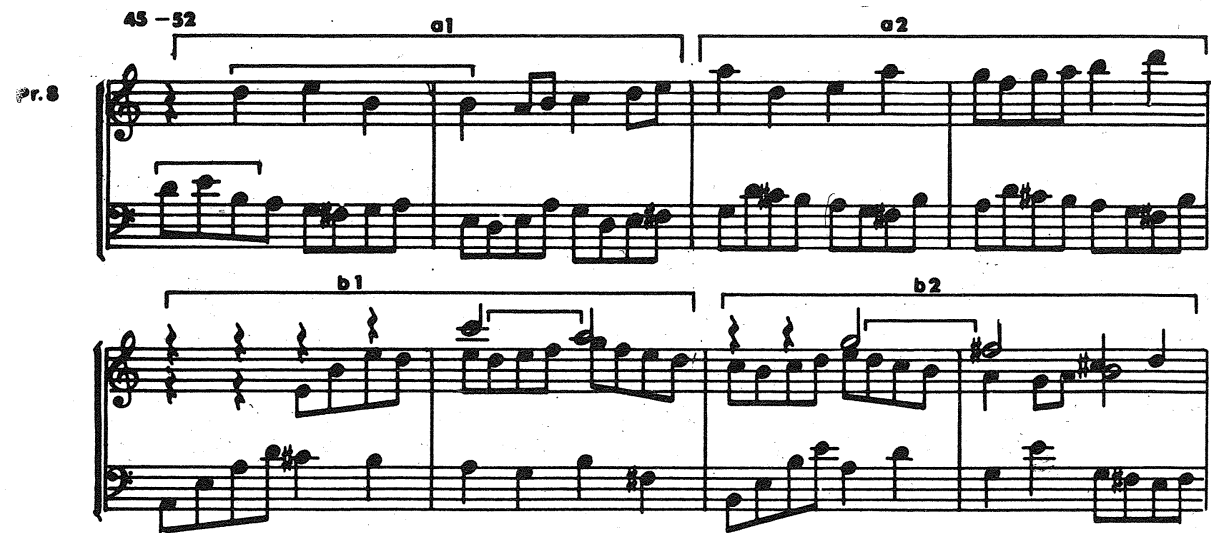

Simetrična struktura prve teme šteje dve mali periodi: $a(a 1+a 2) b(b 1+b 2)$ Glava teme izhaja iz passacaglie (pr. $7 \mathrm{~b} 2$ ), drugi del motiva spominja na tretjo variacijo passacaglie. ${ }^{2}$ Motiv a 2 ima osnovo v osmi variaciji ${ }^{3}$ in prinaša karakteristične intervale (sekundo, kvarto, kvinto). Drugo polovico teme označujeta padajoča mala terca in velika sekunda (pr. 7 b1 in b3). Spremljava v tekočih osminkah ima samo deloma vlogo kontrapunktičnega glasu, le z majhnim imitacijskim deležem. Njen pomen je razmeroma gosta zvočna dopolnitev teme $v$ bitonalni zgradbi, konfrontacija $\mathrm{D}$-dura $\mathrm{z}$ d-molom (načelo nasprotnega $\mathrm{v}$ enotnem).

Nadaljevanje ekspozicije je most $k$ drugi temi. Menjavajo se motivi prve in druge periode $s$ postopnim razpadanjem. Zadnji takt mosta $\mathrm{z}$ imitacijo motiva $\mathrm{b}$ razbije bitonalno jasnost. Paralelna mala septima $v$ oktavah in prekinjena osminska spremljava ustvarita »praznino《 in pot dominantni tonaliteti:

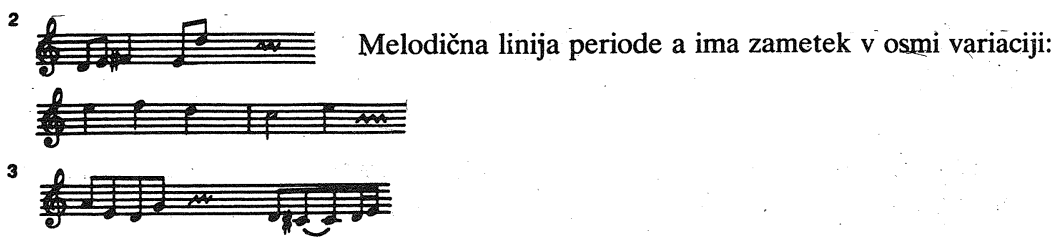




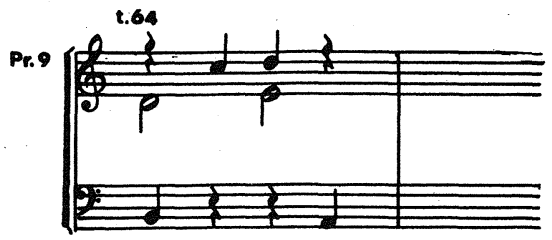

Drugo temo uvaja punktirana kvarta na tonu h (dominanta dominante A-dura in a-mola), ki nakaže ritmično spremembo in novo bitonalno barvo kot kontrast sonatnemu delu $\mathrm{A}$ :

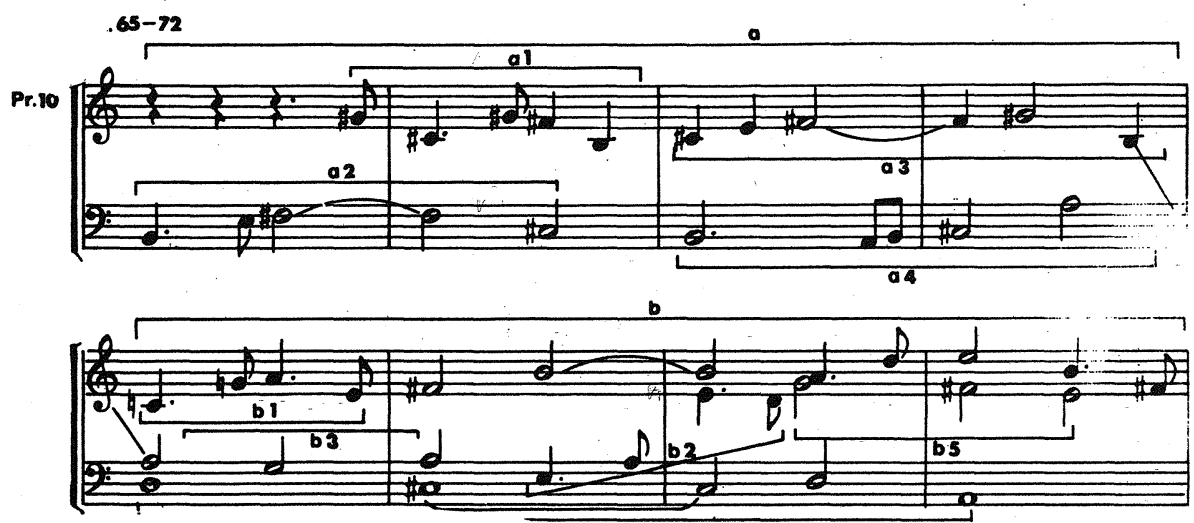

Periodična razdelitev motivov je zopet simetrična, oblikovanje tematike pa izkazuje popolnoma drugačno rešitev povezovania $s$ passacaglio:
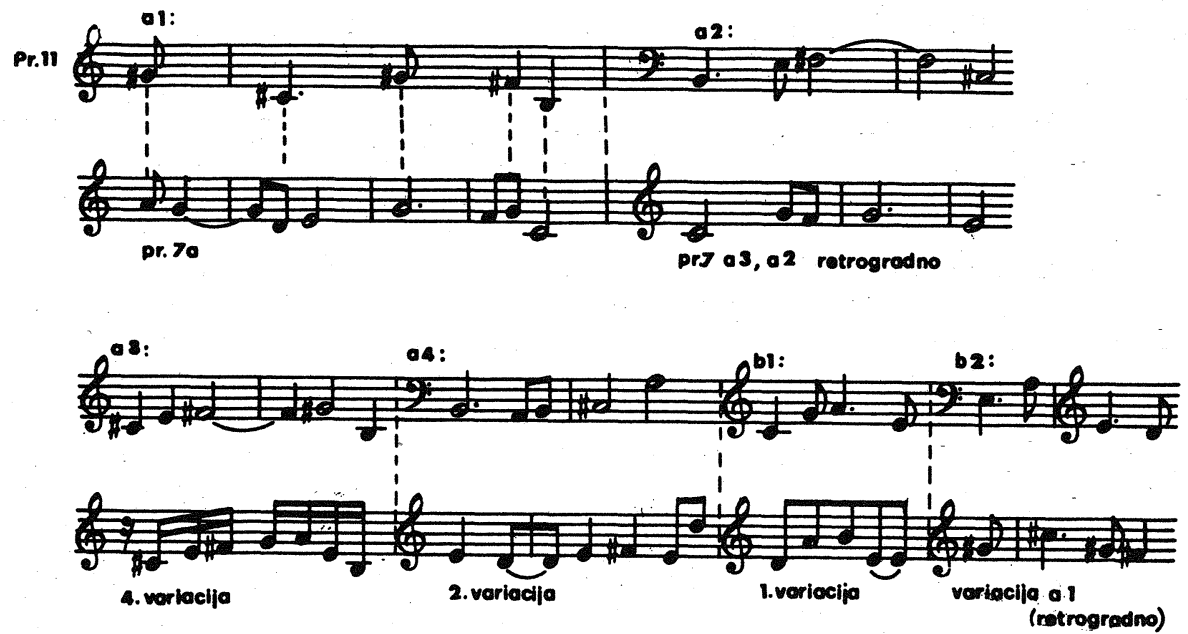


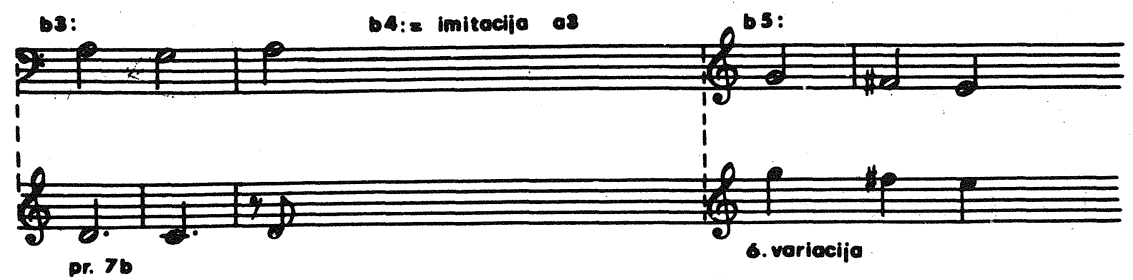

Sorodni in različni fragmenti tokrat nastopajo sočasno kot mešanica fugata in polimelodike $\mathbf{v}$ malem. Analiza razdrobljenosti tematičnih prvin in način medsebojnega spajanja načeloma ne bi imelo smisla (kompozicija je v vsakem primeru postopek kombinacij domislekov), toda nujno postane za razumevanje Sturmove izvedbe kontrasta v ekspoziciji, druge teme v oblikoslovni terminologiji. Izraz tema $\mathbf{v}$ tem primeru ne ustreza popolnoma, ker je oblikovana kot skupek polimelodičnih fragmentov; kombinacija teh $v$ linearnem in vertikalnem gibanju je bolj zvočna gmota kot »tema«. Zavoljo shematične jasnosti vendarle kaže ostati pri tradicionalni oznaki. Motiva a in b imata sicer v zgornjem glasu melodično linijo, ki naj bi spominjala na drugo temo klasicistične sonate, če odštejemo drugačno harmonsko zasnovo (menjavajo se dosledno le: velika sekunda, čista kvarta in kvinta) ${ }^{4}$ brez razvezov, toda $\mathrm{v}$ tem primeru tema ni identična $\mathrm{z}$ melodično linijo, marveč je polimelodični izraz vseh integriranih tematičnih drobcev. Nasproti začetku ekspozicije učinkuje umirjeno in zadržano, kljub allegro tempu. Zdi se, kot bi ustvarjalna fantazija močno bdela nad tem, da se ne bi razvil mehak, lirični (romantični) značaj.

Močna sprememba ritmične in metrične razčlembe ustvarja $v$ tem delu stavka drugačno notno sliko, občutek tretje teme $v$ sonati. Bitonalni odnos je ostal nespremenjen, tematika se veže na predhodno:

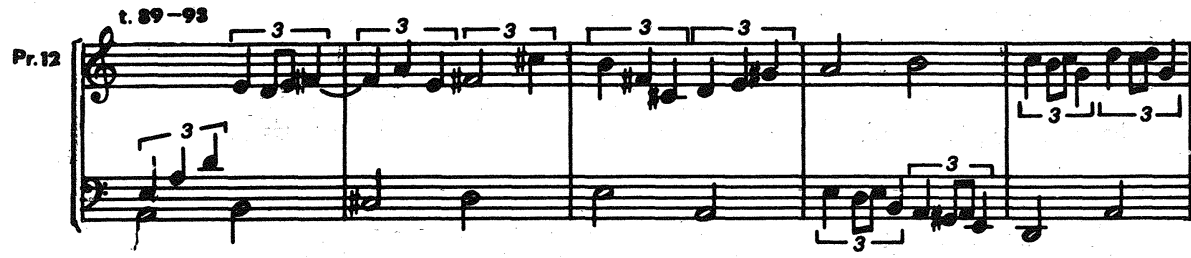

Štiritaktna misel se petkrat ponovi, vsakič nekoliko drugače. Okretno gibanje $v$ triolah prinese novo razpoloženje in daje vtis, da je Šturm $z$ njim nadomestil splošno problematičnost zadnjega stavka $v$ ciklusu sonate. $V$ sklopu ekspozicije sonatnega stavka bi ga mogli tolmačiti kot izdelano tretjo temo, medtem ko tematična gradnja, nespremenjen bitonalni odnos in nekakšna zračnost $v$ strukturi govorijo bolj v prid Sturmovemu poskusu utesnitve rondojskega zametka med tok sonatnega Allegra.

4 Mèd tretjim in četrtim taktom je mala sekunda med $\mathrm{h}$ in c, ampak ton h se veže na srednji glas in kot dominanta dominante v A-duru uvaja srednji glas. To je Šturm sam označil s poševno črtico $\mathrm{v}$ rokopisu. 
Že droben primer kaže, kako metrum figur s tekočimi triolami vnaša $v$ dvodelni ritém tridelnost:

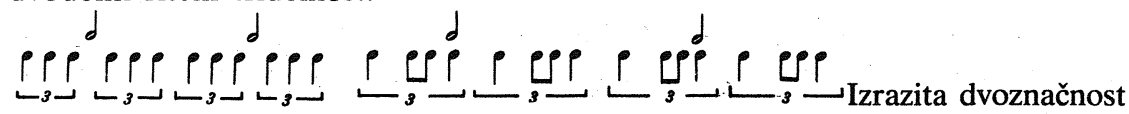
gibanja spominja na učinkovite poliritmične in polimetrične domisleke Stravinskega; doseže nov kolorit $v$ sožitju in razhajanju dveh nasprotnih ritmov - zadržanega, statičnega z živim, plesnim. Metrumski značaj vrivka, dozdevne tretje teme, oblikuje razmerje $2+2: 2 \times 3+3$ kot mešanica scherzoznega in rondojskega utripa - v zunanji formalni zasnovi dve manjkajoči izrazni prvini sonatnega ciklusa.

Začetek izpeljave sklene nizanje malih period $\mathrm{v}$ prehodu tako, da se tok $\mathrm{v}$ triolah nadaljuje še dva takta, $v$ zgornjem glasu pa nastopi motiv prve teme $v$ augmentaciji:

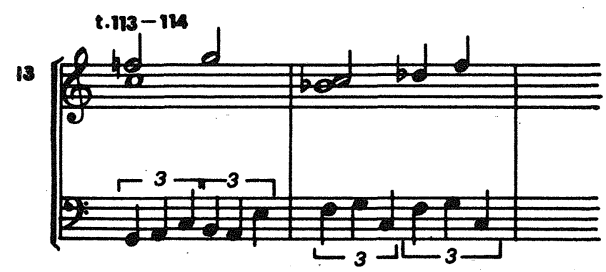

Prehod iz A-dura in a-mola $\mathbf{v}$ - - -mol in c-mol je rešen brez kadence $\mathbf{v}$ podobnem postopku kot pri mostu med prvo in drugo temo.

Izpeljava je grajena po klasicističnem načelu vzpona in razrešitve, tematično delo se ne lovi v rutinskem črpanju fragmentov, izkazuje invencijo vseh temeljnih misli od passacaglie naprej v živem očrtanju njihove glasbe pomenljivosti. Konstrukcijska logika starega oblikovnega in harmonskega nomosa združena $\mathrm{z}$ novim, dopušča skladatelju popolno »svobodo «, se pravi vse in nič. Šturm jo je izpeljal v prepričanju o vedno enaki izrazni sposobnosti in moči glasbe. Protiromantični ideal se tako tudi v izpeljavi ne umakne "prekipevanju " v gradacijah. Sekvence, tonsko slikanje in barvanje, vse to delu ostane do konca tuje. Govorica sonatnega razpleta dosledno nadaljuje izhodiščno zamisel skladbe in redukcijo sredstev. Svobodna imitacija $\mathrm{v}$ členjenju tematičnih skupin in kontrastnih jeder dobi v izpeljavi širše loke in drugačno večznačnost: fugato se razmăhne v druženje vsega predhodnega tematičnega gradiva, sočasnem nastopanju različnih prvin, vodilne misli pa so poudarjene $v$ različnih oblikah kanona. Zvrstijo se domảla vsa prejšnja zvočna območja, bitonalno mešanje v vertikali in horizontali.

Skrčen kanon uvoda in dela prve teme za hip spomni na pripravo reprize, vendar zadnji takt po že znanem nadomestku za kadenco preide v zvočno območje počasnega stavka.

Andante je tridelna pesem. Po značaju je odsev Sostenuta, organizacija polifone strukture spominja deloma na drugo temo, deloma na celo ekspozicijo, vendar sta notranja »teža in obseg obeh tako pretehtana, da je Andante podrejen nižji vrsti tridelnega stavka in ne ruši vsebinskega prestiža ekspozicije.

Analiza tematike pokaže, da so vse prvine v sorodnosti s prejšnjo, da je Šturmovo načelo raznolikosti $v$ enotnem spet dobilo prepričljivo uresničitev. Kompozicijski način modifikacije znanega gradiva v novo podobo se pri posameznih delih 
skladbe razlikuje po tem, koliko močno izrazno spremembo jim je skladatelj namenil $v$ odnosu na notranje ravnovesje ciklusa. Andante ima v tem pogledu podobno težo kot vrivek med ekspozicijo in izpeljavo. Vtis večje samostojnosti je navidezen, ker ima bolj izrazite zunanje znake: oznako tempa (značaja) in ritma.

Začetek stavka zveni takole:
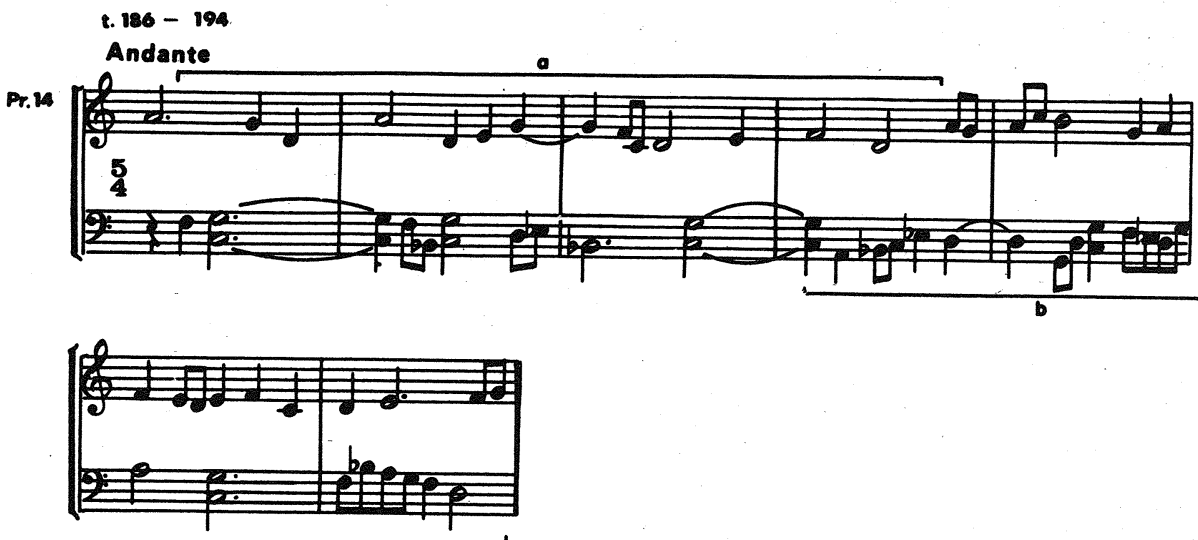

Iz prejšnjih primerov je razviden natančnejši izvor melodičnega obrisa motivov a in b. Ce v kratkem povzamemo: a je augmentirana tema passacaglie, b prerez variacij ostinata, vmesni členi so za stavek drugotnega pomena, manj izpostavljeni, kot gradivo v konstrukciji. Zanimiva je harmonska zasnova: prvi takt zgornjega glasu je identičen začetku passacaglie, ki v osnovni konstelaciji nima opredeljene tonalitete (ima središčni ton d), takoj v nadaljevanju se izlušči jasen C-dur (prim. harmonsko preoblikovanje iste misli $\mathrm{v}$ drugi temi sonatnega stavka, pr. 11 a1). Motiv b nastopi v basovskem glasu kot druga melodična linija. Začne se $z$ malo septimo kakor ostinato v Sostenutu (pr. 7, c1), v drugem taktu izpostavi paralelne kvinte, pentatonsko lestvico pa zamenja c-mol.

Tudi v tem primeru analitično iskanje drobcev $v$ različnih variantah ne bi imelo smisla, če se ne bi nanašalo na umevanje skladateljevega ravnanja $v$ izrazni transformaciji enotnega jedra. V tem oblikovnem členu je Šturm - po vseh opisanih preobrazbah istega - razvil prvič melodiko $\mathrm{v}$ temeljnem, tudi tradicionalnem pomenu besede, pri tem pa doslovno ohranil uvodoma označene lastnosti novega zvoka skladbe. Zdi se, kot bi to varianto namenoma prihranil za praviloma spevni, lirični drugi stavek.

Obe melodični liniji v nadaljevanju oblikujeta prvi del stavká v različnih inačicah svobodne polifonije, ki spominjajo na fragmente iz ekspozicije. Srednji del je krajši, po strukturi se navezuje na prehod od izpeljave $\mathrm{k}$ počasnemu stavku. Ima bolj prehodni kontrastni poudarek kot pomenskega:

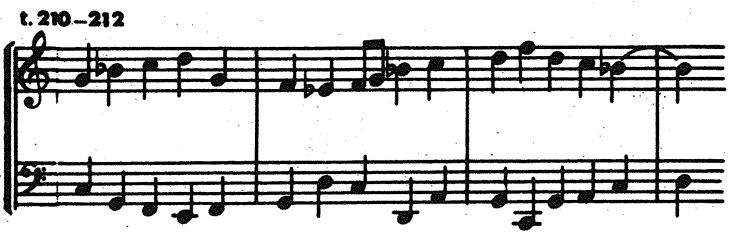


Tretji del stavka (A1) se začne s skrčeno melodično linijo b v zgornjem glasu, ki se izteče $\mathrm{z}$ razpadanjem $\mathrm{v}$ imitaciji. Sklepni del je mala coda $\mathrm{z}$ odsevom zadnje variacije $v$ Sostenutu in postopoma preide $v$ harmonsko območje sonatpega stavka.

Repriza (druga tema je zdaj $v$ toničnem bitonalnem razmerju napram prvi), $v$ načelu prepovedao ponavljanje, pri Šturmovi sonati ne učinkuje kot izhod v sili kot zajamčeno tradicionalno sredstvo za trden sklep formalne zaokroženosti. Koncept ekspozicije kaže, da se je zanjo zavestno odločil ter do kraja izpeljal novo podobo sonate, kjer naj ne manjka nobena med značilnostmi. Gledano z umetniškega stališča, lahko izluščimo, da je Šturm v svojem poskusu sonatnega izraza izpustil le pomensko šibkejše prvine ciklusa: menuet oz. scherzo in zadnji hitri stavek. Poleg tega bi moral $\mathrm{v}$ teh dveh stavkih seči po nazorsko tuji kompozicijski obliki »lažjega «, bolj opisnega značaja, kar bi nevarno posnemalo mnoge poskuse iz 19. stoletja in poznejše, da bi v slogu teh stavkov ustvarili še kaj pomembnega. Zdi se, da je Sturmova zamisel v prehodu od ekspozicije k izpeljavi dovolj zgovorna. V sklepu sonate pred codo jo še utrdi: tok hitrih triol $\mathrm{z}$ metrično delitvijo $2 \times 3+3$ v nekoliko spremenjenem melodičnem obrisu obnovi vtis rondojskega razpoloženja in se zlije $\mathrm{v}$ dvojni kanon, kjer prevladujeta melodika počasnega stavka in passacaglie. Vsebinsko in formalno zaokroženost končno sklene coda $\mathrm{s}$ kratkim ozirom na Andante, temu sledi Allegro, kjer je poudarjena oktavno podvojena prva tema $v$ basovskem glasu, $v$ zgornjih glasovih pa je odmev Sostenuta $s$ paralelnimi kvartami in kvintami, oboje tokrat $\mathrm{v} D$-duru. Ta se $\mathrm{v}$ zadnjih taktih razblini in utrdi temeljno barvo uvodnega stavka $s$ središčnim tonom $d$ :

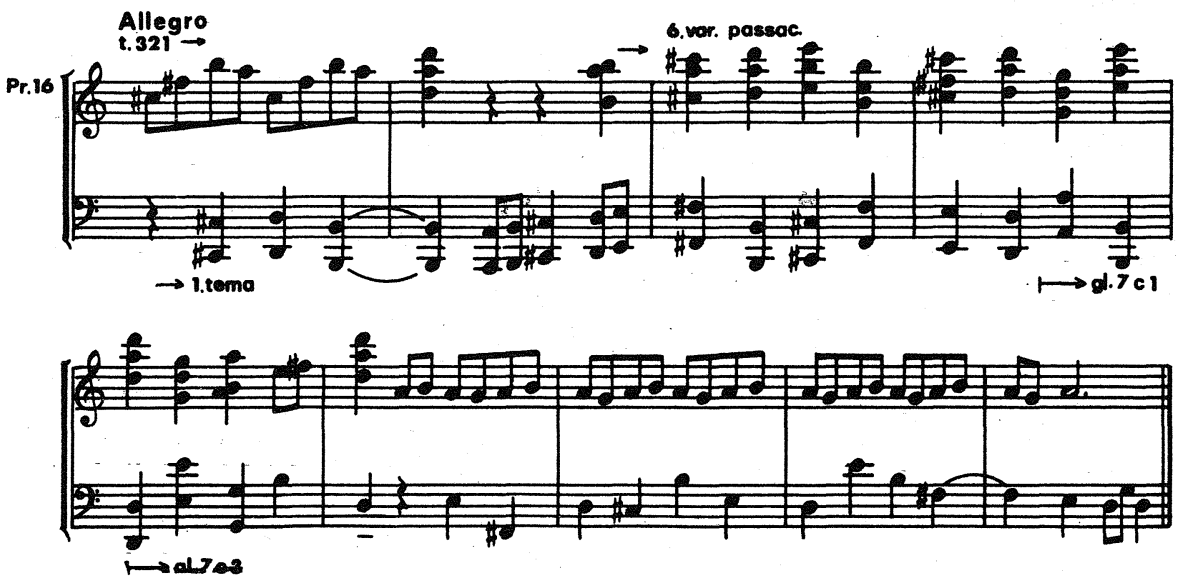

Tudi ta primer nazorno kaže Šturmov smisel za motivično in tematično delo, kjer imajo najmanjši členi vnaprej odmerjeno vlogo. Šesti takt je varianta uvoda $v$ ekspozicijo, $z$ njo pa doseže čisto nov izraz: prvi akord ima zdaj funkcijo zvočnega povratka k izhodišču (prej: znanilo k novi, čeprav sorodni barvi; pr. 6), tekoče osminke reducirajo obseg na tri tone, skupaj $\mathrm{z}$ akordom pa se vrnejo na pentatoniko iz ostinata $v$ prvem stavku (pr. 4). Spremljava v zgornjẹm glasu je skrčena na posamezne tone, skupaj tvorijo sliko značilnih intervalov in bitonalnih menjav, ki se vrnejo $\mathrm{k}$ tonu $\mathrm{d}$. 
Šturmova klavirska Sonata doslej še ni bila predstavljena ne z izvedbo ne v tisku. Skica značilnosti ima namen prikazati osnovne črte kompozicijskega nazora in skladateljeve moči, ki je bila že v prvem ustvarjalnem obdobju nadpovprečna. Podobnega primera klavirske sonate na prelomu izročila $\mathrm{z}$ novo dobo $\mathrm{v}$ znani slovenski literaturi nimamo. Šturm si je zanjo sam našel pot (Osterc je prva izrazitejša dela za klavir - Toccato, Arabeske napisal dve leti pozneje), glede na letnico nastanka pa prispeval vreden delež pri iskanju nove oblike sonate v evropski glasbi med obema vojnama.

\section{SUMMARY}

The composition in question is the eleventh work according to the chronological bibliography of Franc Šturm (1912-1943). It was written after the composer had finished his studies at the Conservatoire with Slavko Osterc. Designed as a cyclic form without interruptions between movements, it is introduced by a Sostenuto (passacaglia with a theme and nine variations), followed by an Allegro (exposition of a sonata movement with introduction and development), an Andante (tripartite slow movement) and a concluding recapitulation of the exposition together with a prolonged coda. An explicitly formal peculiarity is the interpolation between the exposition and development: the would-be third theme of the sonata movement appears to be Šturm's attempt on one hand to condense the missing elements of the sonata, i.e. the generally problematic last movement, and on the other to substitute the sonata menuet or rather scherzo with a characteristic polymetric and polyrhythmic modification $(2+2: 2 \times 3+3)$.

Thematically and regarding the sound the composition grows from the elements of the introductory passacaglia. The filigree arrangement of its motivic elements is designed in such a way as to represent in spite of various thematic and harmonic transformations the embrionic idea of the whole sonata. The principle of variagatedness within homogeneousness is carried out in all compositional parametres. Transformations of the very same material reveal the inventiveness and weight of a composer with a »message«.

The harmonic basis of the composition ensues from the intervals in the passacaglia (major second, inverted also as a minor seventh, minor third, perfect fourth and perfect fifth), whereas the pentatonic basis of the ostinato (without semitone) furnishes an archaic hue as well as the same relation of intervals as the theme proper. The composition flows within a bitonal organization of sound, transitions are carried out without traditional cadences, whereas the tonic-dominant relation between the first and the second theme (in the recapitulation they are both on the tonic) is preserved in the sonata movement.

The composition is a good example of the tendencies of 20th century classics to find 'within the hitherto most highly developed musical form - an adequate framework for expressing elaborated ideas through new means of sound. Sturm's work is part of the avantgarde conglomerate between the two wars which tried to develop a new sonata idiom. The work has not been presented to the public yet. The article wishes thus to elucidate the compositional intentions of an unknown, though first-rate musician. On the verge of the break with tradition there is no other similar piano sonata known in Slovene musical literature. 